\title{
KẾT QUẢ SớM PHẪU THUẬT BẮC CẦU CHỦ VÀNH CẤP CÚU TẠI BỆNH VIỆN TIM HÀ NỘI
}

\author{
Nguyễn Thái Minh*, Nguyễn Hoàng Hà*, Hà Mai Hurong* Hoàng Văn*, Đoàn Quốc Hung**
}

\section{TÓM TẮT}

71 trường hợp được phẫu thuật bắc cầu chủ vành cấp cứu tại Bệnh viện Tim Hà nội từ $1 / 2017$ đến 12/2019. Tuổi trung bình $68,7 \pm 9,3$ (trẻ nhất là 38 tuổi, lớn nhất là 86 tuổi). Nam giới chiếm $66,2 \%$. Euroscore II trung bình là $15,7 \%$. Chỉ định mổ do thiếu máu cơ tim tiến triển mà không can thiệp được chiếm $60,6 \%$, sốc tim do NMCT cấp chiếm $23,9 \%$, các tai biến liên quan đến can thiệp chiếm 7,1\%, biến chứng cơ học sau NMCT cấp chiếm $9,9 \%$. Số cầu nối trung bình là 3,08 . Thời gian cặp ĐMC trung bình là 72 phút (30167), thời gian chạy máy trung bình là 101 phút (40-264). Thời gian thở máy trung bình 4,4 ngày (1-32). Tỷ lệ tử vong bệnh viện là $9,9 \%$. Phẫu thuật bắc cầu chủ vành cấp cứu mặc dù là phẫu thuật có nguy cơ cao nhưng vẫn là một phương pháp điều trị trong một số chỉ định cụ thể với kết quả chấp nhận được.

\section{SUMARRY}

From $01 / 2017$ to $12 / 2019,71$ patients underwent emergency coronary arrtery bypass surgery $(\mathrm{CABG})$ in Hanoi Heart Hospital. Mean age $68,7 \pm 9,3$ years (38-86). $66,2 \%$ of cases was male. Mean Euroscore II value was $15,7 \%$. Surgery indications: developing myocardial infarction (MI) which was unfavourable for percutaneous coronary intervention (PCI): 60,6\%; cardiogenic shock due to acute MI: 23,9\%; complications of PCI: 7,1\%, mechanical complications of MI: 9,9\%. Mean number of bypasses: 3,08. Aortic cross-clamp time: 72 minutes (30-167), cardiopulmonary bypass time: 101 (40-264). Postoperative mechanical ventilation time: 4,4 days (1-32). In-hospital mortality rate: 9,9\%. Conclusion: Emergency CABG, despite a risky choice, was an acceptable treatment for specific acute MI conditions

\section{I. ĐẶT VẤN ĐỀ}

Phẫu thuật bắc cầu chủ vành $(\mathrm{BCCV})$ là một phương pháp điều trị hiệu quả các tổn thương phức tạp của bệnh cơ tim thiếu máu cục bộ.Tuy nhiên, tỷ lệ phẫu thuật $\mathrm{BCCV}$ cấp cứu chiếm một phần nhỏ $5-10 \%$ [1], chủ yếu bao gồm những trường hợp: thiếu máu cơ tim tiến triển mặc dù đã được điều trị nội khoa tối ưu, tổn thương nhiều thân động mạch vành (ĐMV) nặng, tai biến của can thiệp ĐMV qua da, giải phẫu ĐMV không phù hợp cho can thiệp, hay biến chứng cơ học sau NMCT cấp (thủng vách liên thất, hở van hai lá cấp, vỡ thành tự do thất trái). Phẫu thuật $\mathrm{BCCV}$ cấp cứu vẫn là một thách thức lớn đối với bác sĩ ngoại khoa cũng như gây mê hồi sức do tỷ lệ biến chứng sau mổ và tử vong cao [2].

\section{II. ĐỐI TƯợNG VÀ PHƯƠNG PHÁP NGHIÊN CÚU}

Hồi cứu từ 1/1/2017 đến 31/12/2019, tại Bệnh viện Tim Hà Nội, có 764 trường hợp được phẫu thuật bệnh lý ĐMV. Việc lựa chọn BN được phẫu thuật cấp cứu, dựa vào quyết định của 1 nhóm cấp cứu tim mạch gồm phẫu thuật viên, bác sĩ tim mạch can thiệp, bác sĩ nội tim mạch và bác sĩ gây mê hồi sức, căn cứ vào các đặc điểm lâm sàng của bệnh nhân, việc đáp ứng với điều trị nội khoa, sẽ lựa chọn phương pháp tái tưới máu mạch vành. Không đưa vào nghiên cứu những trường hợp phẫu thuật cấp cứu nhưng không có bắc cầu chủ vành (chỉ xử lý các tổn thương cơ học sau $\mathrm{NMCT}$ cấp, khâu cầm máu các tổn thương thủng mạch vành do can thiệp). Như vậy, trong thời

\footnotetext{
* Bệnh viện Tim Hà Nội

** Bệnh viện HN Việt Đức, Truò̀ng Đại học Y Hà Nội Ngưòi chịu trách nhiệm khoa họ: Nguyễn Thái Minh Ngày nhận bài: 02/08/2020 - Ngày Cho Phép Đăng: 04/09/2020 Phản Biện Khoa học: PGS.TS. Đặng Ngọc Hùng PGS.TS. Nguyễn Hũu U'óc
} 
gian trên có 71 trường hợp (chiếm 9,3\%) được thỏa mãn yêu cầu trên. Nghiên cứu mô tả 1 loạt ca bệnh, tính tỷ lệ các biến giới rời rạc như các biến thể hiện đặc điểm lâm sàng và cận lâm sàng trước mổ, các chỉ định mổ cấp cứu, các biến chứng thường gặp sau mổ, tỷ lệ tử vong trong bệnh viện và các nguyên nhân tử vong. Tính trung bình cho các biến số liên tục như tuổi, Euroscore II, chỉ số khối cơ thể, các thông số đo đạc trên siêu âm tim, thời gian chính cuộc mổ (thời gian liệt tim, thời gian chạy THNCT), thời gian thở máy, thời gian điều trị...

\section{KẾT QUẢ}

Tuổi trung bình $68,7 \pm 9,3$ (trẻ nhất là 38 tuổi, lớn nhất là 86 tuổi). Bệnh nhân $(\mathrm{BN})$ trên 70 tuổi chiếm $53,5 \%$, trong đó $8,5 \%$ BN trên 80 tuổi. Tỷ lệ nam giới chiếm $66,2 \%$. BMI trung bình $21,5 \pm 3,1 \mathrm{~kg} / \mathrm{m}^{2}$ (nhỏ nhất là 13,6 lớn nhất là 30,1). Điểm Euroscore II trung bình là $14,69 \pm 13,57 \%$ (nhỏ nhất là 0,95 - lớn nhất là 53,20$)$.

Các yếu tố nguy cơ và bệnh phối hợp của $\mathrm{BN}$ trước mổ được thể hiện trong bảng 1 .

Bảng 1. Các yếu tố nguy cơ và bệnh phối hợp

\begin{tabular}{|l|c|}
\hline Đặc điểm & Số lượng(\%) \\
\hline Tăng huyết áp & $65(91,5)$ \\
\hline Tiểu đường & $24(33,8)$ \\
\hline Rối loạn chuyển hóa lipid & $28(39,4)$ \\
\hline Hút thuốc lá & $32(45,1)$ \\
\hline Bệnh phổi tắc nghẽn mạn tính & $4(5,6)$ \\
\hline Tiền sử tai biến mạch não & $6(8,5)$ \\
\hline Bệnh mạch máu ngoại vi & $16(22,5)$ \\
\hline Tiền sử can thiệp mạch vành & $10(14,1)$ \\
\hline
\end{tabular}

Đặc điểm lâm sàng trước mổ, hay gặp nhất là triệu chứng đau ngực theo phân loại của hội tim mạch Canada (CCS) mức độ 4 chiếm 81,7\%. 42,3\% được mổ trong bệnh cảnh NMCT có ST chênh lên. Gần $1 / 3$ số $\mathrm{BN}$ phải thở máy trước mổ do suy tim và suy hô hấp nặng. Về thuốc chống ngưng tập tiểu cầu được sử dụng ở hầu như tất cả các bệnh nhân, đáng chú ý là hơn $70 \%$ số $\mathrm{BN}$ được sử dụng thêm Plavix và hơn $1 / 3$ số $\mathrm{BN}$ được sử dụng Brillinta trước mổ. Các đặc điểm lâm sàng cụ thể được thể hiện ở bảng 2 .

Bảng 2. Một số đặc điểm trước mổ

\begin{tabular}{|l|l|c|}
\hline \multicolumn{2}{|c|}{ Đặc điểm } & Số lượng (\%) \\
\hline \multirow{2}{*}{$\begin{array}{l}\text { Thay đổi đoạn } \\
\text { STT trên ĐTĐ }\end{array}$} & Không STT chênh lên & $41(57,7)$ \\
\cline { 2 - 3 } & STT chênh lên * & $30(42,3)$ \\
\hline \multirow{2}{*}{$\begin{array}{l}\text { Mức độ đau ngực } \\
\text { theo CCS }\end{array}$} & 3 & $13(18,3)$ \\
\cline { 2 - 3 } & 4 & $58(81,7)$ \\
\hline
\end{tabular}




\begin{tabular}{|l|l|c|}
\hline \multirow{5}{*}{} & $\begin{array}{l}\text { Loạn nhịp nguy hiểm (nhanh thất, rung thất, } \\
\text { ngừng tim) }\end{array}$ & $5(7)$ \\
\cline { 2 - 3 } & Suy hô hấp phải thở máy đến khi mổ & $20(28,2)$ \\
\cline { 2 - 3 } & Thuốc trợ tim/vận mạch liều cao & $6(8,5)$ \\
\cline { 2 - 3 } & Bóng đối xung ĐMC & $1(1,4)$ \\
\cline { 2 - 3 } & Cấp cứu ngừng tuần hoàn & $1(1,4)$ \\
\hline \multirow{4}{*}{$\begin{array}{l}\text { Thuốc chống } \\
\text { ngưng tập tiểu cầu } \\
\text { trước mố }\end{array}$} & Không dùng & $2(2,8)$ \\
\cline { 2 - 3 } & Aspirin & $69(97,2)$ \\
\cline { 2 - 3 } & Kèm Plavix & $26(77,5)$ \\
\cline { 2 - 3 } & Kèm Brilinta & $26,6)$ \\
\hline
\end{tabular}

CCS (Canadian Cardiovascular Society): Hội tim mạch Canada; ĐMC: động mạch chủ; ĐTĐ: điện tâm đồ; *: có 21 BN NMCT thành truớc/ bên, 9 BN NMCT thành duới.

Kết quả chụp ĐMV trước mổ thể hiện ở bảng 3, cho thấy chủ yếu BN có tổn thương 3 thân.

Bảng 3. Tổn thương động mạch vành

\begin{tabular}{|l|c|}
\hline Tổn thương mạch vành & Số lưộng(\%) \\
\hline Thân chung & $4(5,6)$ \\
\hline 3 thân có thân chung & $33(46,5)$ \\
\hline 3 thân không có thân chung & $25(35,2)$ \\
\hline 2 thân không có thân chung & $2(2,8)$ \\
\hline 1 thân & $7(9,9)$ \\
\hline
\end{tabular}

Trên siêu âm tim, Phân suất tống máu trung bình là $47 \pm 15,9 \%$ (thấp nhất $20 \%$, cao nhất là $76 \%$ ). Đường kính thất trái cuối tâm trương (Dd) là 48,6 $\pm 7,1 \mathrm{~mm}$ (thấp nhất là 33 , cao nhất là 67 ). Áp lực động mạch phổi tâm thu trung bình là 32,4 $\pm 9,6 \mathrm{mmHg}$ (thấp nhất là 20 , cao nhất là 60 ). $26 / 71(35,7 \%) \mathrm{BN}$ có tổn thương van hai lá từ $2 / 4$ trở lên, trong đó 4 trường hợp có tổn thương thực thể. Có $2 \mathrm{BN}$ có tổn thương thủng vách liên thất sau NMCT cấp và $6 \mathrm{BN}$ trên siêu âm có nhiều dịch máu màng tim, trong đó 2 trường hợp vỡ thành tự do thất trái và 4 trường hợp có thủng mạch vành sau can thiệp.

Xét nghiệm các chỉ số liên quan đến tổn thương NMCT và suy tim cho kết quả, Troponin T độ nhạy cao, CK-MB và NT ProBNP lần lượt là $1707,7 \pm 3303,7$ ng/L (12,0 - 22159,0), 88,36士 115,3U/L (6,4 - 658), $4498,9 \pm 58508 \mathrm{pg} / \mathrm{L}(92-35000)$.

Về chỉ định mổ cấp cứu, 41 BN $(57,1 \%)$ được chỉ định mổ trong tình huống NMCT tiến triển không đáp ứng với điều trị nội khoa, $17 \mathrm{BN}$ $(23,9 \%)$ NMCT có sốc tim nhưng giải phẫu mạch vành không phù hợp cho can thiệp, $6 \mathrm{BN}$ 
$(8,4 \%)$ là tai biến của can thiệp tim mạch trong đó 4 ca thủng ĐMV, 2 ca lóc ĐMV, còn lại 7 BN có biến chứng cơ học sau NMCT cấp $(9,9 \%)$, trong đó 3 ca vỡ thành tự do thất trái, 2 ca hở hai lá cấp do đứt cột cơ van hai lá và 2 ca thủng vách liên thất sau NMCT cấp. Biểu đồ 1 thể hiện chỉ định mổ của $71 \mathrm{BN}$.

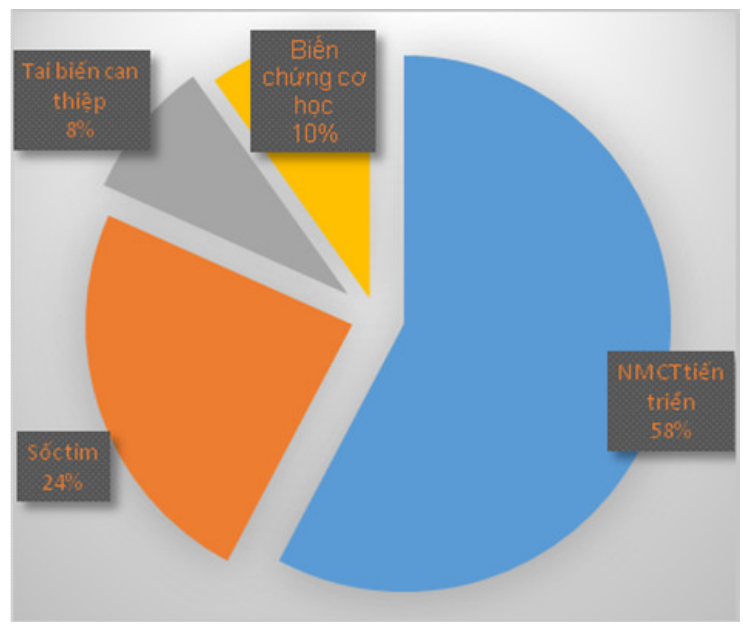

Biểu đồ 1. Chỉ định mổ

Tuyệt đại đa số bệnh nhân được phẫu thuật dưới tuần hoàn ngoài cơ thể (70/71 bệnh nhân). Có 2 trường hợp chạy THNCT nhưng không liệt tim. Số lượng cầu nối chủ vành trung bình là $3 \pm 1$ (ít nhất là 1 cầu, nhiều nhất là 5 cầu). $55 \mathrm{BN}(77,5 \%)$ được lấy động mạch vú trong trái làm cầu nối, $68 \mathrm{BN}$ $(95,8)$ được lấy $\mathrm{TM}$ hiển và $5 \mathrm{BN}$ được sử dụng $\mathrm{ĐM}$ quay làm cầu nối.

Thời gian cặp ĐMC trung bình là $72 \pm 26$ phút, nhanh nhất là 30 phút, chậm nhất là 167 phút. Thời gian chạy THNCT trung bình là $101 \pm 37$ phút (nhanh nhất là 40, chậm nhất là 264 phút).

Ngoài việc $\mathrm{BCCV}$, có $20 \mathrm{BN}$ được làm thêm các phẫu thuật đi kèm. Chi tiết trong bảng 4 .

Bảng 4. Các phẫu thuật đi kèm

\begin{tabular}{|l|c|}
\hline Phẫu thuật đi kèm & Số lượng (\%) \\
\hline Vá thất trái & $3(4,2)$ \\
\hline Vá thủng vách liên thất & $2(2,8)$ \\
\hline Sửa VHL do đứt dây chằng & $2(2,8)$ \\
\hline Sửa VHL do tổn thương thiếu máu & $6(8,5)$ \\
\hline Thay van ĐMC & $2(2,8)$ \\
\hline Sửa van ba lá & $4(5,6)$ \\
\hline Khác* & $3(4,2)$ \\
\hline
\end{tabular}

VHL: Van hai lá; ĐMC: động mạch chủ; ĐM: động mạch; *: 1 ca thay van hai lá, 1 ca bóc nội mạch động mạch cảnh, 1 ca láy huyết khối ĐM phổi

$8 \mathrm{BN}(11,3 \%)$ cần hỗ trợ bóng đối xung nội ĐMC để ngừng THNCT, không có trường hợp nào phải đặt ECMO. 
Trung bình dẫn lưu trung thất sau mổ 24 giờ là 452,8 $\pm 450,6 \mathrm{ml}$ (ít nhất là $60 \mathrm{ml}$, nhiều nhất là $1930 \mathrm{ml}$ ). Thời gian thở máy trung bình là 4,4 $\pm 5,4$ ngày (sớm nhất là 1 ngày, lâu nhất là 32 ngày). 7 $\mathrm{BN}$ phải đặt lại nội khí quản do suy hô hấp sau khi rút nội khí quản lần 1.1 Bệnh nhân cần hỗ trợ ECMO trong giai đoạn nằm hồi sức. Chi tiết các biến chứng sau mổ thể hiện ở bảng 5 .

Bảng 5. Các biến chứng sau mổ

\begin{tabular}{|l|c|c|}
\hline Biến chứng & Số lượng & (\%) \\
\hline Chảy máu, máu cục mổ lại & 7 & 9,9 \\
\hline Rung thất & 8 & 11,3 \\
\hline Viêm phổi & 12 & 16,9 \\
\hline Tai biến mạch não & 3 & 4,2 \\
\hline Loạn thần & 4 & 5,6 \\
\hline Suy thận cần lọc máu & 9 & 12,7 \\
\hline Nhiễm khuẩn huyết & 4 & 5,6 \\
\hline Xuất huyết tiêu hóa nặng & 3 & 4,2 \\
\hline Viêm phúc mạc & 1 & 1,4 \\
\hline Nhiễm trùng xương ức & 2 & 2,8 \\
\hline Nhiễm trùng vết mổ & 10 & 14,8 \\
\hline
\end{tabular}

7/71 $\mathrm{BN}(9,9 \%)$ tử vong trong bệnh viện, có 3 trường hợp do suy tim nặng, còn 4 trường hợp khác tử vong do các nguyên nhân không phải tim mạch (3 $\mathrm{BN}$ xuất huyết tiêu hóa và $1 \mathrm{BN}$ sốc nhiễm trùng do nhiễm khuẩn huyết).

$64 \mathrm{BN}$ còn lại (chiếm 90,1\%) ổn định ra viện, với thời gian điều trị trung bình là 16,5 \pm 9,3 ngày, ngắn nhất là 3 ngày, muộn nhất là 56 ngày.

\section{BÀN LUẬN}

Các yếu tố như chỉ định phẫu thuật BCCV cấp cứu, thời điểm phẫu thuật, phương pháp phẫu thuật và những vấn đề điều trị, theo dõi bệnh nhân $\mathrm{HCĐMVC} \mathrm{liên} \mathrm{tục} \mathrm{được} \mathrm{nghiên} \mathrm{cứu} \mathrm{và} \mathrm{cập}$ nhật trong suốt 15 đến 20 năm qua.

Vî̀ chỉ định mổ, bao gồm các nhóm chính như sau:

- Can thiệp qua da không thành công và tái tưới máu không hoàn toàn. Với những trường hợp này, nếu giải phẫu mạch vành phù hợp và nguy cơ phẫu thuật không quá cao, có thể cân nhắc để phẫu thuật BCCV. Thực tế, một tỷ lệ không nhỏ $\mathrm{BN}$ NMCT cấp bị tổn thương nặng nhiều thân
ĐMV, can thiệp sẽ gặp khó khăn hoặc kết quả lâu dài không tốt. Nhiều nghiên cứu cho thấy, tỷ lệ tử vong trong phẫu thuật $\mathrm{BCCV}$ cấp cứu trong nhóm $\mathrm{NMCT}$ cấp có và không $\mathrm{ST}$ chênh cho kết quả khả quan ngay cả trong trường hợp có sốc tim [3],[4]. Trong nghiên cứu của chúng tôi, $17 \mathrm{BN}$ (chiếm 23,9\%), được chỉ định mổ trong tình huống sốc tim sau khi chụp ĐMV mà giải phẫu ĐMV không phù hợp cho can thiệp hoặc không xác định rõ ràng nhánh mạch thủ phạm. Trong nhóm này có $2 \mathrm{BN}$ được nong bóng tạm thời nhánh thủ phạm (1 $\mathrm{BN}$ được nong nhánh ĐM liên thất trước, $1 \mathrm{BN}$ được nong ĐMV phải) sau đó chuyển mổ cấp cứu. Can thiệp - phẫu thuật phối hợp (Hybrid) cũng là một lựa chọn phù hợp trong 
những tình huống tổn thương mạch vành nhiều thân trong đó xác định được rõ nhánh thủ phạm. Hybrid giúp nhanh chóng tái tưới máu nhánh thủ phạm, việc phẫu thuật để tái tưới máu những nhánh còn lại được thực hiện sau một thời gian, giúp giảm thiểu nguy cơ phẫu thuật. Thực tế là, trong nhiều trường hợp việc quyết định mổ còn bị ảnh hưởng bởi khả năng chi trả của $\mathrm{BN}$, mức độ sẵn sàng và sự thành thạo trong nhóm phẫu thuật cấp cứu. Khi đã xác định không thể tái tưới máu toàn bộ bằng can thiệp mạch vành, nhiều $\mathrm{BN}$ chúng tôi tiến hành ngay phẫu thuật cấp cứu, dựa trên quyết định của 1 nhóm bác sĩ có kinh nghiệm (phẫu thuật viên, bác sĩ nội khoa, bác sĩ can thiệp và gây mê hồi sức).

Một chỉ định mổ không phổ biến, nhưng ngày càng gặp nhiều hơn khi số lượng can thiệp mạch vành tăng dần theo thời gian, đó là những biến chứng của can thiệp như lóc ĐMV, thủng ĐMV, tắc sớm trong stent, gãy, gập stent... trong đó hay gặp là thủng và lóc ĐMV. Trong nghiên cứu này, có $6 \mathrm{BN}$ (chiếm 8,4\%) thuộc chỉ định mổ do tai biến của can thiệp, trong đó $4 \mathrm{BN}$ thủng ĐMV gây tràn máu màng tim cấp - ép tim và $2 B N$ lóc $Đ M V(1 B N$ lóc thân chung và 1 BN lóc ĐMV phải). Trong báo cáo của Erin M. Schumer và cộng sự về $\mathrm{BCCV}$ cấp cứu từ năm 2003 đến 2013, thấy rằng, giai đoạn 2003-2008, chỉ định mổ cấp cứu do tai biến của can thiệp chỉ là 5,3\%, sang giai đoạn 2008-2013, tỷ lệ này tăng lên đáng kể $(29,5 \%)$ [3]. Chúng tôi nghĩ rằng, thực tế, tỷ lệ này có thể cao hơn, vì đây là hồi cứu những $\mathrm{BN}$ đã được phẫu thuật, những trường hợp tai biến của can thiệp nhưng $\mathrm{BN}$ không kịp mổ cấp cứu hoặc không đồng ý mổ thì không được thống kê.

- NMCT hoặc thiếu máu cơ tim tiến triển khi đã tối ưu hóa điều trị nội khoa và giải phẫu mạch vành không phù hợp cho can thiệp là chỉ định chiếm đa số trong phẫu thuật $\mathrm{BCCV}$ cấp cứu. Ngoài ra, bệnh tiểu đường phối hợp, phân suất tống máu thất trái thấp, mức độ sẵn sàng phẫu thuật cấp cứu của từng cơ sở, là những yếu tố góp phần quyết định chỉ định phẫu thuật ở nhóm bệnh nhân này kể cả khi chưa có dấu hiệu thiếu máu tiến triển[5]. Tỷ lệ này trong nghiên cứu của Erin M. Schumer chiếm 61,5\% giai đoạn 2008-2013 và 78,2\% giai đoạn 2003-2008. Trong nghiên cứu của chúng tôi, $57,1 \% \mathrm{BN}$ phẫu thuật $\mathrm{BCCV}$ cấp cứu là điều trị tái tưới máu thì đầu cho BN NMCT cấp.

- Các biến chứng cơ học sau NMCT cấp là một trong những chỉ định tuyệt đối của phẫu thuật. Tần suất gặp các biến chứng này trước kỷ nguyên tiêu sợi huyết và can thiệp ĐMV qua da khá cao: vỡ thành tự do thất trái (2-4\%), hở van hai lá cấp và thủng vách liên thất $(1-2 \%)$ [6]. Mặc dù cant thiệp mạch vành có thể thực hiện tái tưới máu nhanh nhánh thủ phạm nhưng không cải thiện nhiều về huyết động do các biến chứng cơ học gây ra. Trong một số trường hợp, có thể can thiệp nhánh thủ phạm nếu kịp thời, sau đó sẽ phẫu thuật sửa tổn thương cơ học và bắc cầu các nhánh tổn thương khác không phải thủ phạm. Tuy nhiên, trong trường hợp vỡ thành tự do thất trái hay thủng vách liên thất, cách làm này ít hiệu quả, có 2 lý do, thứ nhất không đủ thời gian can thiệp (đặc biệt trong vỡ thành tự do thất trái), thứ hai là vùng thiếu máu của nhánh thủ phạm thường là không cứu vãn được, và vấn đề ưu tiên lúc này là xử lý tổn thương cơ học để phục hồi huyết động. Trong nghiên cứu này của chúng tôi, có $7 \mathrm{BN}$ được mổ do biến chứng cơ học của NMCT cấp. Khi làm nghiên cứu, chúng tôi chỉ lấy những $\mathrm{BN}$ có $\mathrm{BCCV}$ kèm theo, nhưng thực tế, số $\mathrm{BN}$ được phẫu thuật sửa chữa biến chứng cơ học đơn thuần mà không $\mathrm{BCCV}$ cao hơn nhiều. 


\section{Thời điểm phẫu thuật}

Thời điểm phẫu thuật lý tưởng trong phẫu thuật BCCV sau NMCT cấp còn nhiều tranh cãi. Một số trường hợp tương đối rõ ràng như: sốc tim, biến chứng cơ học sau NMCT cấp hay thiếu máu tiến triển không đáp ứng với các biện pháp khác. Ngoài các tình huống trên, thời điểm thích hợp để phẫu thuật sau NMCT cấp còn chưa rõ ràng. Mặc dù, tái tưới máu sớm bằng phẫu thuật có ưu điểm hạn chế kích thước vùng nhồi máu, hạn chế việc xảy ra biến chứng cơ học sau $\mathrm{NMCT}$, tuy nhiên việc này cũng đối diện với nguy cơ gây tổn thương do tái tưới máu sớm. Tổn thương tái tưới máu có thể gây ra xuất huyết trên vùng nhồi máu, lan rộng vùng nhồi máu và làm vùng sẹo nhồi máu lớn hơn. Kể cả khi phẫu thuật có dùng THNCT hay không, phẫu thuật quá sớm có thể gây ra sự trầm trọng hơn đáp ứng viêm hệ thống tại vùng NMCT.

Nghiên cứu lớn của Lee [7], cho thấy tỷ lệ tử vong sau mổ ở nhóm NMCT có ST chênh lên hay không ST chênh lên đều thấp như nhau và bằng $3,1 \%$. Khi phân tích đến yếu tố thời gian từ khi xuất hiện NMCT đến khi mổ thì thấy tỷ lệ tử vong cao hơn ở nhóm NMCT có ST chênh lên nếu mổ trong vòng 7 ngày sau nhồi máu. Phân tích đa biến cho kết quả, mổ trong vòng 1 ngày đối với $\mathrm{NMCT}$ có $\mathrm{ST}$ chênh và trong vòng 6 giờ với NMCT không ST chênh là yếu tố nguy cơ độc lập làm tăng tỷ lệ tử vong.

Tuy nhiên, trong nghiên cứu Monteiro [8], phẫu thuật sớm thậm chí trong nhóm bệnh nhân nguy cơ cao vẫn cho kết quả tốt với tỷ lệ tử vong trong bệnh viện rất thấp, do đó tác giả cho rằng thời gian trì hoãn phẫu thuật không ảnh hưởng nhiều đến kết quả.

Khi so sánh giữa 2 phương pháp bắc cầu chủ vành có sử dụng THNCT hay không, tác giả Kaya cho rằng, bệnh nhân được mổ trong vòng 6 giờ kể từ khi khởi phát đau ngực ('giờ vàng') vẫn rất khả thi và cho kết quả tốt [9].

Trong nghiên cứu của chúng tôi, về lựa chọn đối tượng đã xác định là $\mathrm{BN}$ được chỉ định mổ cấp cứu, là các tình huống thuộc nhóm không trì hoãn, do đó vấn đề thời điểm phẫu thuật nào là lý tưởng không có nhiều ý nghĩa.

Các đặc điểm trước mổ, nhóm $\mathrm{BN}$ được phẫu thuật $\mathrm{BCCV}$ cấp cứu cũng có một số đặc điểm đặc thù so với những $\mathrm{BN}$ được mổ theo kế hoạch:

- Thuốc chống ngưng tập tiểu cầu (TCNTTC): tuyệt đại đa số $\mathrm{BN}$ được sử dụng TCNTTC (Aspirin đơn độc 97,2\%, phối hợp Clopidogrel 77,5\%, phối hợp Ticargrelor chiếm $36,6 \%$ ). TCNTTC, đặc biệt là liệu pháp kép (phối hợp Clopidogrel hoặc Ticargrelor) được sử dụng với $\mathrm{BN}$ NMCT cấp, trong và sau can thiệp mạch vành giúp làm giảm các biến chứng nhồi máu hay tắc stent. Lợi ích của TCNTTC rất tốt ngay cả trong trường hợp chỉ điều trị nội khoa, can thiệp đặt stent hay phẫu thuật BCCV. Tuy nhiên, để giảm các biến chứng chảy máu sau mổ, 2 thuốc này được khuyến cáo dừng trước ít nhất 24 giờ trước mổ (khuyến cáo mức I của hội Tim mạch Châu Âu năm 2014) [10]. Trong nghiên cứu của chúng tôi, đa số $\mathrm{BN}$ được mổ cấp cứu mà không có thời gian để ngừng TCNTTC như theo khuyến cáo.

- Bóng đối xung động mạch chủ (BĐXĐMC): được sử dụng với những $\mathrm{BN}$ huyết động không ổn định, giúp cải thiện tưới máu mạch vành và giảm nhu cầu oxy cơ tim. Những nghiên cứu ban đầu cho kết quả giảm tỷ lệ tử vong sớm. Tuy nhiên, trong nghiên cứu rất lớn gần đây IABP-SHOCK II, trong nhóm sốc tim do NMCT cấp được sử dụng $\mathrm{BĐXĐMC} \mathrm{hay} \mathrm{không} \mathrm{được} \mathrm{sử}$ dụng, không làm thay đổi khác biêt về tỷ lệ tử vong sớm [11]. Chúng tôi chủ trương với những trường hợp huyết động không ổn định trước mổ, cố gắng duy trì huyết động bằng thuốc và nhanh 
chóng triển khai mổ cấp cứu, BĐXĐMC sẽ được chuẩn bị sẵn sàng tại phòng mổ hoặc khoa nơi $\mathrm{BN}$ chuẩn bị mổ, sẽ đặt bóng nếu sau mổ không cai được THNCT. Chỉ có 1 BN phải đặt BĐXĐMC trước mổ. Số còn lại, một là không có thời gian, hai là huyết động vẫn giữ được bằng thuốc.

Các biến chúng sớm sau mổ, trong tình huống mổ cấp cứu, thường là nhóm bệnh nhân rất nặng, thời gian chuẩn bị mổ hạn chế, phẫu thuật thường phức tạp và kéo dài, do đó tỷ lệ các biến chứng sau mổ cao.

- Chảy máu là mối quan tâm của hầu hết phẫu thuật viên khi mổ cấp cứu. Trong nghiên cứu của chúng tôi, trung bình mỗi $\mathrm{BN}$ chảy gần $500 \mathrm{ml}$ máu ở ngày đầu sau mổ, trong đó có $7 \mathrm{BN}$ phải mổ lại vì chảy máu chiếm tỷ lệ khá cao là $9,9 \%$. Đa số BN được dùng TCNTTC kép đến khi mổ, do đó tỷ lệ chảy máu sau mổ cao đã được xác định từ trước và có thể giải thích được. Tỷ lệ này trong nghiên cứu của Khaladj [4], và Schumer [3] là 7\%, 5,7 \%. Chảy máu sau mổ trong những $\mathrm{BN}$ mổ $\mathrm{BCCV}$ cấp cứu, ngoài nguyên nhân do sử dụng TCNTTC trước mổ, còn liên quan đến các yếu tố khác như: tuổi cao, cân nặng thấp, có thiếu máu trước mổ, có các bệnh lý rối loạn đông máu di truyền, cuộc mổ phức tạp và kéo dài... Chảy máu sau mổ, cần phải truyền máu (đặc biệt là máu đã bảo quản lâu), dù chỉ $1-2$ đơn vị, là nguyên nhân kéo theo nhiều biến chứng sớm khác sau mổ như : rung nhĩ, suy thận, viêm phổi, nhiễm trùng, suy tim và biến chứng thần kinh... làm kéo dài thời gian thở máy, ảnh hưởng lớn không những đến kết quả sớm mà còn kết quả lâu dài sau mổ. Tương tự với những trường hợp phải mổ lại do chảy máu cũng làm tăng biến chứng và tăng tỷ lệ tử vong sau mổ [12]. Điều này cũng lý giải, tỷ lệ những biến chứng như viêm phổi, rung nhĩ, suy thận cần lọc máu trong nghiên cứu của chúng tôi đều cao.
- Các biến chứng nặng về tiêu hóa, chúng tôi gặp với tỷ lệ khá cao $(5,6 \%)$, trong đó 3 BN (4,2\%) gặp xuất huyết tiêu hóa (XHTH) nặng và $1 \mathrm{BN}$ bị viêm phúc mạc sau mổ. Biến chứng này khá thường gặp sau phẫu thuật tim, chiếm tỷ lệ 2,9 - 4,6 \% tùy nghiên cứu [13],[14]. Biến chứng này gặp ngày càng nhiều, do tuổi $\mathrm{BN}$ ngày càng cao, nhiều bệnh lý phối hợp và mức độ phức tạp ngày càng tăng của các phẫu thuật tim. Một số tác giả chỉ ra mối liên quan giữa điểm Euroscore với khả năng có biến chứng tiêu hóa sau mổ, hay việc sử dụng các biện pháp hỗ trợ cơ học như BĐXĐM [13]. Trong 3 BN XHTH nặng của chúng tôi, đều có điểm Euroscore II rất cao: 39,27\%, 42,91\% và 44,18\%. 2 trong số $3 \mathrm{BN}$ này được đặt $\mathrm{BĐXĐMC.} \mathrm{Yếu} \mathrm{tố} \mathrm{thúc} \mathrm{đẩy} \mathrm{XHTH} \mathrm{thường} \mathrm{là}$ tình trạng rối loạn đông máu sau mổ, tình trạng thiếu máu mạc treo. Nhiều tác giả nhận xét rằng tỷ lệ tử vong trên $75 \%$ trong nhóm $\mathrm{BN}$ này [13]. Cả 3 BN XHTH nặng sau mổ của chúng tôi đều tử vong.

Vì tỷ lệ tủ vong bệnh viện, là một trong những yếu tố quan trọng biểu hiện kết quả sớm của phẫu thuật đều khá cao tùy nghiên cứu. Nếu như trước đây, tỷ lệ này đến $20 \%$ [15],[16], nguyên nhân gây tử vong chủ yếu là suy tim nặng, suy đa tạng và nhiễm khuẩn huyết. Gần đây, với sự tiến bộ trong phẫu thuật, gây mê hồi sức, tỷ lệ tử vong trong nhóm phẫu thuật cấp cứu giảm đi đáng kể, trong nghiên cứu của Khaladj có kết quả khả quan nhất, chỉ $6 \% \mathrm{BN}$ tử vong trong 30 ngày điều trị, các yếu tố bao gồm: sốc tim trước mổ, phải đặt $\mathrm{BĐXĐMC} \mathrm{trước} \mathrm{mổ,} \mathrm{EF}$ thấp, NMCT ST chênh, điểm Euroscore cao trước mổ làm tăng nguy cơ tử vong. Trong nghiên cứu của chúng tôi, tỷ lệ tử vong bệnh viện là $9,9 \%$, với điểm Euroscore II trung bình là $14,69 \%$, có thể thấy rằng tỷ lệ tử vong trong 
nhóm $\mathrm{BN}$ của chúng tôi thấp hơn so với thang điểm dự báo. Ngoài ra, có $23,9 \% \mathrm{BN}$ có sốc tim trước mổ và $9,9 \%$ được phẫu thuật sửa chữa biến chứng cơ học sau NMCT cấp, là những tình huống rất nặng, nguy cơ tử vong cao. Như vậy, chúng tôi thấy rằng, tỷ lệ tử vong trong nghiên cứu của chúng tôi là chấp nhận được.

\section{KẾT LUẬN}

Phẫu thuật $\mathrm{BCCV}$ cấp cứu vẫn luôn là thách thức trong điều trị bệnh lý ĐMV với tỷ lệ biến chứng và tử vong sau mổ cao. Tuy nhiên, cùng với sự phát triển của các kỹ thuật mổ, khả năng về gây mê hồi sức, kết quả phẫu thuật $\mathrm{BCCV}$ cấp cứu vẫn chấp nhận được, và là một trong những lựa chọn tốt khi điều trị nội khoa và can thiệp không kết quả.

\section{TÀI LIỆU THAM KHẢO}

1. American College of Emergency Physicians; Society of Cardiovascular Angiography and Interventions, O.G.P., Kushner FG, Ascheim DD, Casey DE Jr, et al $A H A$ guideline for the management of ST-elevation myocardial infarction: a report of the American College of Cardiology Foundation/American Heart Association Task Force on Practice Guidelines. J Am Coll Cardiol 2013, 2013. 61(4): p. e78-140.

2. Gu YL, Van der Horst IC, Douglas YL, et al, Role of coronary artery bypass grafting during the acute and subacute phase of STelevation myocardial infarction. Neth Heart J, 2010. 18: p. 348-54.

3. Schumer E. M, Chaney J. H, Trivedi J. R, et al., Emergency Coronary Artery Bypass Grafting: Indications and Outcomes from 2003 through 2013. Tex Heart Inst J, 2016. 43(3): p. 214-9.

4. Khaladj N, Bobylev D, Peterss S, et al, Immediate surgical coronary revascularisation in patients presenting with acute myocardial infarction. J Cardiothorac Surg, 2013. 8: p. 167.

5. Shi W.Y. and Smith J.A., Role of Coronary Artery Bypass Surgery in Acute Myocardial Infarction, in Primary Angioplasty: A Practical Guide, O.P. Watson TJ, Tcheng JE, Editor. 2018 Springer: Singapore.

6. Wang W., Cheung A, Mechanical Complications of Acute Myocardial Infraction, in Primary Angioplasty: A Practical Guide O.P. Watson TJ, Tcheng JE,, Editor. 2018, Springer: Singapore.

7. Lee D.C, Oz M.C, Weiberg A.D, et al, Optimal timing of revascularization: Transmural versus nontransmural acute myocardial infarction. . Ann Thorac Surg 2001. 71: p. 1198-204.

8. Monteiro P., Impact of early coronary artery bypass graft in an unselected acute coronary syndrome patient population. Circulation, 2006. 114(1 Suppl): p. I467-72.

9. Kaya K., Cavolli R., Telli A., et al., Offpump versus on-pump coronary artery bypass grafting in acute coronary syndrome: a clinical analysis. J Cardiothorac Surg, 2010. 5: p. 31.

10. Stephan K., Philippe A., Fernando C., et al., 2014 ESC/EACTS Guidelines on myocardial revascularization: The Task Force on Myocardial Revascularization of the European Society of Cardiology (ESC) and the European Association for Cardio-Thoracic Surgery (EACTS)Developed with the special contribution of the European Association of Percutaneous Cardiovascular Interventions (EAPCI). European Heart Journal, 2014. 35(37): p. 2541-2619.

11. Thiele H., Zeymer U., Neumann F. J., et al., Intra-aortic balloon counterpulsation in acute myocardial infarction complicated by cardiogenic shock (IABP-SHOCK II): final 12 
month results of a randomised, open-label trial. Lancet, 2013. 382(9905): p. 1638-45.

12. Fitchett D., Eikelboom J., Fremes S., et al., Dual antiplatelet therapy in patients requiring urgent coronary artery bypass grafting surgery: a position statement of the Canadian Cardiovascular Society. Can J Cardiol, 2009. 25(12): p. 683-9.

13. Marsoner K., Voetsch A., Lierzer C., et al., Gastrointestinal complications following onpump cardiac surgery - A propensity matched analysis. PLOS ONE, 2019. 14(6): p. e0217874.

14. Haywood N., Mehaffey J. H., Hawkins R. B., et al., Gastrointestinal Complications After Cardiac Surgery: Highly Morbid but Improving
Over Time. Journal of Surgical Research, 2020. 254: p. 306-313.

15. Hagl C., Khaladj N., Peterss S., et al., Acute treatment of ST-segment-elevation myocardial infarction: is there a role for the cardiac surgeon? Ann Thorac Surg, 2009. 88(6): p. 1786-92.

16. Niranjan S., Patrick L. W, Naveen A., et al., Emergency Coronary Artery Bypass Surgery in the Contemporary Percutaneous Coronary Intervention Era. Circulation, 2002. 106(18): p. 2346-2350. 